\title{
Comunicação \\ Desempenho de porta-enxertos em diferentes sistemas de cultivo na produção de mudas do pessegueiro 'Chimarrita'
}

\author{
Juliano Dutra Schmitz, Mateus da Silveira Pasa², Doralice Lobato de Oliveira Fischer², \\ José Carlos Fachinello ${ }^{3}$, Valmor João Bianchi ${ }^{4}$
}

\begin{abstract}
RESUMO
O presente trabalho teve como objetivo verificar o desempenho dos porta-enxertos 'Okinawa' e 'Capdeboscq', em três sistemas de cultivo, na produção de mudas do pessegueiro 'Chimarrita'. O experimento foi instalado em viveiro comercial no município de Pelotas-RS. O período de avaliação compreendeu desde a semeadura, realizada em 12 de julho de 2010, até a avaliação final das mudas enxertadas, 365 dias após a semeadura, em julho do ano subsequente. Os tratamentos constituíram-se de dois porta-enxertos, 'Okinawa' e 'Capdeboscq', e três sistemas de cultivo, onde eles foram plantados: exclusivamente em campo, sobre bancadas em ambiente aberto e sobre bancadas dentro de telado com cobertura plástica. Para o delineamento experimental dos tratamentos utilizou-se a casualização por blocos com fatorial 2 × 3 (dois porta-enxertos e três sistemas de cultivo, respectivamente). Com este estudo, conclui-se que é possível produzir mudas de 'Chimarrita', com vigor similar, utilizando os porta-enxertos 'Capdeboscq' e 'Okinawa'. Assim, o sistema de cultivo em campo proporciona mudas mais vigorosas, independentemente do porta-enxerto utilizado.
\end{abstract}

Palavras-chave: Prunus, sementes, propagação, enxertia.

\section{ABSTRACT}

\section{Performance of peach rootstocks in different crop systems for the production of 'Chimarrita' seedlings}

The aim of this study was to evaluate the performance of 'Okinawa' and 'Capdeboscq' peach rootstocks in three crop systems for the production of 'Chimarrita' seedlings. The assay was installed in commercial nursery at Pelotas. The evaluation period was from seeding, in 12 July 2010, until the next year, 365 days after seeding, in July 2011. The treatments consisted of two rootstocks: 'Okinawa' and 'Capdeboscq'; and three crop systems: exclusively in the field, on the benches outside the greenhouse, on benches inside the greenhouse and with plastic covering. The experiment was arranged in a in a $2 \times 3$ factorial (two rootstocks and three crop systems, respectively) randomized block design. In this study, it was possible to produce seedlings of 'Chimarrita' with similar vigor using the rootstocks 'Okinawa' and 'Capdeboscq'. Besides, the system in field provide more vigorous scions regardless of the rootstock

used.

Key words: Prunus, seeds, propagation, grafting.

Recebido para publicação em 22/03/2013 e aprovado em 06/08/2013.

${ }^{1}$ Este trabalho é parte da dissertação de mestrado do primeiro autor. Financiada pelo Conselho Nacional de Desenvolvimento Científico e Tecnológico.

'Engenheiros-Agrônomos, Mestres. Departamento de Fitotecnia, Universidade Federal de Pelotas, 354, 96010-900, Pelotas, Rio Grande do Sul, Brasil. jdsagro@gmail.com (autor para correspondência); mateus.pasa@gmail.com

${ }^{2}$ Engenheira-Agrônoma, Doutora. Instituto Federal Sul Rio Grandense, Campus Pelotas-Visconde da Graça, Avenida Engenheiro Ildefonso Simões Lopes, 2791, 96060-290, Pelotas, Rio Grande do Sul, Brasil. doralicefischer@yahoo.com.br

${ }^{3}$ Engenheiro-Agrônomo, Doutor. Departamento de Fitotecnia, Universidade Federal de Pelotas, 354, 96010-900, Pelotas, Rio Grande do Sul, Brasil. jfachi@ufpel.edu.br

${ }^{4}$ Engenheiro-Agrônomo, Doutor. Departamento de Botânica, Universidade Federal de Pelotas, 354, 96010-900, Pelotas, Rio Grande do Sul, Brasil. valmorjb@yahoo.com 


\section{INTRODUÇÃO}

A qualidade das mudas para a formação do pomar está entre os principais fatores que conduzem ao sucesso na produção de frutas. Mudas de qualidade, associadas ao adequado manejo fitotécnico do pomar, determinam a produtividade e, consequentemente, o retorno econômico do capital investido (Fachinello et al., 2005; Chagas et al., 2008). O Rio Grande do Sul é o maior produtor de pêssegos (Prunus persica (L.) Batsch) do Brasil, sendo responsável por 65\% da produção total em 2009 (Fachinello et al., 2011). Além disso, este Estado possui grande tradição na produção de mudas, as quais são obtidas principalmente em viveiros no campo.

Mundialmente, os porta-enxertos da maioria das frutíferas de caroço ainda são propagados por sementes (Malcolm et al., 2003). Da mesma forma, o pessegueiro no Brasil vem sendo multiplicado pela técnica da enxertia em seedlings da mesma espécie.

Além da facilidade de propagação, fatores como adaptação ao clima e solo da região de cultivo, compatibilidade com os principais cultivares copa, redução do porte da planta e incremento de produtividade são características agronômicas almejadas em porta-enxertos dessa espécie (Chagas et al., 2008). Nesse sentido, os porta-enxertos 'Okinawa' e 'Capdeboscq' possuem grande potencial de utilização nas regiões Sul e Sudeste do Brasil (Mayer \& Pereira, 2006; Rocha et al., 2007; Picolotto et al., 2009; Comiotto et al., 2012).

A identificação de porta-enxertos adequados às diversas condições edafoclimáticas de cultivo e o seu desempenho inicial em diferentes condições de viveiro, são de grande interesse pelo setor produtivo de mudas. Devido a limitantes de ordem fitossanitária, a rotação das áreas dos viveiros é extremamente necessária para a produção de mudas de alto padrão de qualidade. Logo, a adoção de técnicas que possibilitem a otimização da infraestrutura do viveiro é necessária. O cultivo em condições controladas, como em casas de vegetação e telados, tem proporcionado maior precocidade na produção de diversas culturas, bem como aumento da qualidade dos produtos obtidos (Reis et al., 2010).

Assim, o objetivo deste trabalho foi verificar o desempenho dos porta-enxertos 'Okinawa' e 'Capdeboscq', em três sistemas de cultivo, na produção de mudas do pessegueiro 'Chimarrita'.

\section{MATERIAL E MÉTODOS}

O experimento foi conduzido em viveiro comercial, em Pelotas-RS (31 ${ }^{\circ}$-32' S; 52 -23' O; Altitude: 102 m). O período de avaliação compreendeu todo o ciclo de produção das mudas, ou seja, desde a semeadura, realizada em 12 de julho de 2010, até a avaliação final das mudas enxertadas em julho de 2011, totalizando 365 dias.
Os tratamentos foram dispostos na área experimental por meio da casualização por blocos no esquema fatorial 2 x 3 (dois porta-enxertos e três sistemas de cultivo). Cada parcela foi constituída por 10 unidades de observação, em um total de cinco repetições por tratamento. $\mathrm{O}$ fator porta-enxerto foi composto por dois níveis: 'Okinawa' e 'Capdeboscq', os quais foram multiplicados por sementes (seedlings). Eles foram combinados em três sistemas de plantio, em que os níveis foram: cultivo exclusivamente em campo, sobre bancadas em ambiente aberto (bancada) e sobre bancadas dentro de telado com cobertura plástica (telado).

Para o cultivo em bancada e telado, a semeadura foi realizada em sacos de plástico com volume de 4,5 L contendo substrato comercial da marca Plantmax ${ }^{\circledR}$. No cultivo em campo, a semeadura foi realizada diretamente nas linhas de cultivo no espaçamento 100 x $12 \mathrm{~cm}(100 \mathrm{~cm}$ entre linhas e $12 \mathrm{~cm}$ entre sementes na linha). Em todas as modalidades a semeadura foi realizada a $1 \mathrm{~cm}$ de profundidade.

As sementes de ambos os porta-enxertos foram estratificadas por três meses antes da semeadura, em câmara frigorífica a $5^{\circ} \mathrm{C}$, com umidade de $90 \%$ e ausência de luz. O porta-enxerto 'Okinawa' foi utilizado, principalmente, devido à resistência aos fitonematoides e a sua grande demanda de mudas para o cultivo do pessegueiro em regiões de baixo acúmulo de frio hibernal, como a região Sudeste do Brasil. Por outro lado, 'Capdeboscq', antigo cultivar de indústria, foi escolhido por ter sido tradicionalmente utilizado por longo tempo como porta-enxerto no Estado do Rio Grande do Sul, por apresentar boa taxa de germinação e bom desempenho no viveiro em campo.

Os porta-enxertos foram enxertados com o cultivar copa 'Chimarrita' pela técnica de borbulhia de gema ativa na forma de "T invertido" aos 154 dias após a semeadura e na altura de $15 \mathrm{~cm}$ a partir do nível do solo.

As variáveis respostas avaliadas ao longo do desenvolvimento das mudas foram: porcentagem média de emergência (\%), avaliada por meio da contagem semanal das plântulas emergidas; e altura inicial dos seedlings $(\mathrm{cm})$, mensurada imediatamente após o término da emergência, aos 58 dias após a semeadura. No momento da enxertia, 154 dias após a semeadura, foram avaliados: diâmetro de tronco dos seedlings $(\mathrm{mm})$, mensurado $10 \mathrm{~cm}$ a partir do colo das plantas, com auxílio de paquímetro digital; altura dos seedlings $(\mathrm{cm})$, do colo das plantas até o ápice da gema terminal; e número de ramificações laterais dos seedlings até $30 \mathrm{~cm}$ a partir do colo. Avaliou-se a porcentagem média de enxertos brotados aos 37 dias após a enxertia. Ao término do experimento, 365 dias após a semeadura, avaliou-se o diâmetro de tronco $(5 \mathrm{~cm}$ abaixo e 5 $\mathrm{cm}$ acima do ponto de enxertia), com auxílio de paquímetro digital, e a altura final da muda enxertada, com fita métrica.

Para a análise estatística, os dados expressos em porcentagem foram transformados para o Arco Seno (x) $1 / 2$ e 
os expressos em contagem foram transformados por meio da expressão $(x+1) 1 / 2$, sendo " $x$ " o valor das repetições de cada variável resposta em ambas as fórmulas. Para interpretação dos resultados foi realizada análise de variância, e quando essas foram significativas, fez-se comparação de médias pelo teste de Duncan $(p=0,05)$.

\section{RESULTADOS E DISCUSSÃO}

Independentemente do sistema de cultivo, o portaenxerto 'Capdeboscq' apresentou maior porcentagem média de emergência e altura inicial aos 58 dias após a semeadura (Tabela 1). Considerando o fator sistema de cultivo, observou-se em campo a maior porcentagem de plântulas emersas e no cultivo em telado a maior altura inicial para ambos os porta-enxertos aos 58 dias após a semeadura (Tabela 1). O fator que pode ter influenciado na maior porcentagem média de emergência e vigor inicial até os 58 dias após a semeadura de 'Capdeboscq' é o fato de o mesmo possuir apenas uma semente no endocarpo e com maior massa, e 'Okinawa' possui, em média, duas sementes e de menor massa. Segundo Malcolm et al. (2003), sementes de maior tamanho e massa têm maior porcentagem de germinação e emergência. Além disso, estudando o desenvolvimento de mudas de tamarindeiro, Almeida et al. (2010) concluíram que a utilização de sementes com maior massa proporciona melhor desenvolvimento inicial das mudas, como foi verificado no presente trabalho com o porta-enxerto 'Capdeboscq'.

O substrato também tem influência na formação de porta-enxertos para pessegueiro (Wagner Júnior et al., 2007). Assim, a menor porcentagem de emergência nos sistemas de cultivo em telado e bancada pode ter sido influenciada pelo substrato empregado, pois segundo esses autores, que também usaram o substrato Plantmax ${ }^{\circledR}$ na formação de mudas de pessegueiro, esse substrato não é o mais apropriado, necessitando de ajustes na composição, principalmente para adequar à disponibilidade de água tanto para a emergência quanto para o desenvolvimento posterior. No presente experimento, foi observado excesso de retenção de umidade, o que foi extrema- mente danoso aos seedlings de porta-enxertos na fase inicial de crescimento.

O diâmetro do tronco do porta-enxerto é a medida fundamental que determina o momento que ele pode ser enxertado. No presente experimento, 'Capdeboscq' apresentou maior diâmetro no momento da enxertia (Tabela 1). Segundo Wagner Júnior et al. (2007), na produção de mudas de pessegueiro é interessante que os porta-enxertos tenham crescimento rápido tanto em altura quanto em espessura do tronco, visando assim apresentar condições adequadas para serem enxertados. Essa resposta foi estreitamente relacionada ao maior vigor até os 58 dias após a semeadura de 'Capdeboscq'.

Os diferentes sistemas de cultivo não influenciaram o diâmetro do tronco no momento da enxertia. Resultado semelhante foi relatado por Picolotto et al. (2007), os quais verificaram que o período para produção de mudas de pessegueiro em sacos plásticos foi muito semelhante ao realizado em campo. Com esses resultados, verificou-se que é possível obter seedlings de porta-enxertos para pessegueiro com diâmetro de tronco similar e adequado para enxertia, num mesmo período de tempo, tanto no cultivo em campo quanto em sacos plásticos mantidos em ambiente controlado.

Não foram observadas diferenças de altura entre os porta-enxertos aos 154 dias após a semeadura. Por outro lado, a maior altura de plantas foi obtida com o sistema de cultivo em bancadas em ambiente aberto (Tabela 1). Essa resposta pode estar relacionada à menor competição por luz entre os porta-enxertos cultivados em campo, devido ao espaçamento ser maior, de 100 x $12 \mathrm{~cm}$. Já na situação de cultivo em ambiente aberto e telado, o espaçamento entre as plantas foi de $30 \times 30 \mathrm{~cm}$, ou seja, possivelmente houve maior competição para captação de radiação e, consequentemente, tendência de as plantas crescerem mais em altura. Para a variável número de ramificações até $30 \mathrm{~cm}$ a partir do nível do solo, não houve diferenças entre 'Capdeboscq' e 'Okinawa' (Tabela 1). Entretanto, verificou-se efeito do fator sistema de plantio, em que o maior número de ramificações nos seedlings até $30 \mathrm{~cm}$ do nível do solo foi observado no cultivo em campo, e esse

Tabela 1. Porcentagem média de emergência (EM), altura inicial aos 58 dias após a semeadura (ALTi), número de ramificações até $30 \mathrm{~cm}$ de altura (R30), diâmetro do tronco (DIA) e altura (ALT) no momento da enxertia de seedlings dos porta-enxertos 'Okinawa' e 'Capdeboscq', em diferentes sistemas de cultivo, Pelotas - RS, 2012

\begin{tabular}{lccccc}
\hline & $\begin{array}{l}\text { EM } \\
(\%)\end{array}$ & $\begin{array}{l}\text { ALTi } \\
(\mathbf{c m})\end{array}$ & $\mathbf{R 3 0}$ & $\begin{array}{c}\text { DIA } \\
(\mathbf{m m})\end{array}$ & $\begin{array}{c}\text { ALT } \\
(\mathbf{c m})\end{array}$ \\
\hline Capdeboscq & $73 \mathrm{a}$ & $15,30 \mathrm{a}$ & $10,10^{\mathrm{ns}}$ & $7,14 \mathrm{a}$ & $88,24^{\mathrm{ns}}$ \\
Okinawa & $56 \mathrm{~b}$ & $12,72 \mathrm{~b}$ & 10,25 & $6,23 \mathrm{~b}$ & 81,74 \\
\hline Campo & $85 \mathrm{a}$ & $11,67 \mathrm{~b}$ & $11,78 \mathrm{a}$ & $6,52^{\mathrm{ns}}$ & $71,04 \mathrm{c}$ \\
Telado & $46 \mathrm{~b}$ & $19,44 \mathrm{a}$ & $8,6 \mathrm{~b}$ & 6,82 & $81,29 \mathrm{~b}$ \\
Bancada & $63 \mathrm{~b}$ & $10,94 \mathrm{~b}$ & $10,16 \mathrm{ab}$ & 6,72 & $102,65 \mathrm{a}$ \\
\hline CV(\%) & 22,96 & 20,45 & 10,11 & 12,78 & 10,69 \\
\hline
\end{tabular}

*Médias seguidas de letras iguais, nas colunas, não diferem significativamente pelo teste de Duncan $(p=0,05)$. ns: não significativo $(p=0,05)$. 
sistema só diferenciou do sistema de cultivo em telado (Tabela 1). Este propiciou menor número de ramificações laterais, sendo um aspecto extremamente positivo, pois o pequeno número de ramificações nessa região do portaenxerto implica em menor mão de obra com a retirada dos ramos laterais no momento da enxertia, agilizando a operação e reduzindo os custos de produção, além de evitar estresse demasiado por efeito das lesões provocadas pelos cortes. As plantas produzidas sobre o sistema em telado possuíram maior dominância apical, ou seja, controle exercido pela gema apical do ramo sobre as gemas laterais ao longo do mesmo, impedindo-as de brotarem (Cline, 1997).

Não houve efeito dos diferentes porta-enxertos sobre a porcentagem média de enxertos brotados de 'Chimarrita' aos 37 dias após a enxertia (Tabela 2). A falta de influência dos porta-enxertos nessa variável resposta pode ser explicada por tratar de materiais oriundos de pé-franco (Prunus persica (L.) Batsch), tendo de maneira geral seedlings de pessegueiro apresentado boa compatibilidade de enxertia com os cultivares copa produzidos no Brasil. Segundo Telles et al. (2006), genótipos com similaridade genética e morfológica desenvolvem proliferação de células meristemáticas e parenquimáticas com afinidades para a formação de um novo sistema vascular, motivo que leva ao sucesso da enxertia. Porém, o sistema de cultivo em campo proporcionou maior porcentagem de enxertos brotados (Tabela 2). Na avaliação realizada ao final do período de crescimento e desenvolvimento das mudas, 365 dias após a semeadura, foi possível observar o equilíbrio do vigor dos porta-enxertos e de 'Chimarrita' pelo diâmetro do tronco medido $5 \mathrm{~cm}$ abaixo do ponto de enxertia e na altura final das mudas, e não foi observada diferença entre os porta-enxertos (Tabela 2). O porta-enxerto 'Okinawa', segundo Reis et al. (2010), é considerado vigoroso, porém, estudando 'Chimarrita', Rocha et al. (2007) verificaram que 'Capdeboscq' foi mais vigoroso que 'Okinawa'. No presente estudo, constatou-se que 'Capdeboscq' apresentou vigor inicial superior até o momento da enxertia, porém, na análise final, 'Okinawa' teve vigor similar. $\mathrm{O}$ atraso inicial e a compensação de crescimento de 'Okinawa' quando comparado a 'Capdeboscq' é uma informação de grande utilidade a fim de estimar o vigor e a qualidade do porta-enxerto.

A maior porcentagem de brotação e o vigor final das mudas no sistema de cultivo em campo estão, muito provavelmente, relacionados ao desenvolvimento do sistema radicular. Assim, o cultivo em campo possui o sistema radicular diretamente ancorado ao solo, o que permite maior potencial do seu crescimento. Por outro lado, plantas produzidas em sacos de plástico têm o sistema radicular limitado pelo volume do recipiente. Assim, plantas cultivadas em campo, em que o sistema radicular possui maior potencial de crescimento e desenvolvimento, podem ter apresentado respostas significativas de brotação dos enxertos e vigor final da muda enxertada, em razão de o sistema radicular ser responsável não somente pela sustentação da planta, captação de água e nutrientes, mas também é fundamental no armazenamento de reservas, principalmente o amido, e na produção de fitohormônios responsáveis por divisão celular, como as citocininas (Basile et al., 2006).

Tabela 2. Porcentagem média de enxertos brotados (EB), diâmetro do porta-enxerto $5 \mathrm{~cm}$ abaixo do ponto de enxertia (DIAPE), diâmetro do enxerto $5 \mathrm{~cm}$ acima do ponto de enxertia (DIAE) e altura final (ALTF) das mudas de 'Chimarrita' enxertas sobre os portaenxertos 'Okinawa' e 'Capdeboscq', em diferentes sistemas de cultivo, Pelotas - RS, 2012

\begin{tabular}{llccc}
\hline & $\begin{array}{c}\text { EB } \\
(\boldsymbol{\%})\end{array}$ & $\begin{array}{c}\text { DIAPE } \\
(\mathbf{m m})\end{array}$ & $\begin{array}{c}\text { DIAE } \\
(\mathbf{m m})\end{array}$ & $\begin{array}{c}\text { ALTF } \\
(\mathbf{c m})\end{array}$ \\
\hline Capdeboscq & $65,22^{\text {ns }}$ & $9,59^{\text {ns }}$ & $6,27^{\text {ns }}$ & $53,98^{\text {ns }}$ \\
Okinawa & 78,88 & 8,93 & 5,79 & 52,97 \\
\hline Campo & $90 \mathrm{a}$ & $10,46 \mathrm{a}$ & $8,17 \mathrm{a}$ & $75,57 \mathrm{a}$ \\
Telado & $62,1 \mathrm{~b}$ & $8,70 \mathrm{~b}$ & $4,62 \mathrm{~b}$ & $36,11 \mathrm{c}$ \\
Bancada & $64 \mathrm{~b}$ & $8,64 \mathrm{~b}$ & $5,29 \mathrm{~b}$ & $48,76 \mathrm{~b}$ \\
\hline CV(\%) & 28,17 & 11,51 & 21,64 & 22,18 \\
\hline
\end{tabular}

"Médias seguidas de letras iguais, nas colunas, não diferem significativamente pelo teste de Duncan $(p=0,05)$. ns: não significativo $(p=0,05)$.

\section{CONCLUSÕES}

É possível produzir mudas de 'Chimarrita' com vigor similar utilizando os porta-enxertos 'Capdeboscq' e 'Okinawa'.

O sistema de cultivo no campo proporciona mudas mais vigorosas, independentemente do porta-enxerto utilizado.

\section{REFERÊNCIAS}

Almeida MS de, Melo B de, Silva CA da, Santana DG de \& Silva CJ da (2010) Massa de sementes e profundidades de semeadura no desenvolvimento de mudas de tamarindeiro. Revista Brasileira de Fruticultura, 32:555-560.

Basile B, Bryla DR, Salsman ML, Marsal J, Cirillo C, Johson RS \& Dejong TM (2006) Growth patterns and morphology of fine roots of size-controlling and invigorating peach rootstocks. Scientia Horticulturae, 27:231-241. 
Chagas EA, Pio R, Bettio Neto JE, Sobierajski GR, Campo Dall'Orto FA \& Signorini G (2008) Enraizamento de estacas lenhosas de pessegueiro e clones de umezeiros submetidos à aplicação de AIB. Ciência e Agrotecnologia, 32:986-991.

Cline GM (1997) Concepts and terminology of apical dominance. American Journal of Botany, 9:1064-1069.

Comiotto A, Fachinello JC, Hoffmann A, Machado NP, Galarça SP \& Betemps DL (2012) Vigor, floração, produção e qualidade de pêssegos 'Chimarrita' e 'Maciel' em função de diferentes porta-enxertos. Ciencia Rural, 42:788-794.

Fachinello JC, Hoffmann A \& Nachtigal JC (2005) Propagação de plantas frutíferas. Brasília, Embrapa Informação Tecnológica. $221 \mathrm{p}$.

Fachinello JC, Pasa M da S, Schmitz JD \& Betemps DL (2011) Situação e perspectivas da fruticultura de clima temperado no Brasil. Revista Brasileira de Fruticultura, 33:109-120.

Malcolm PJ, Holford P, McGlasson WB \& Newman S (2003) Temperature and seed weight affect the germination of peach rootstock seeds and the growth of rootstock seedlings. Scientia Horticulturae, 98:247-256.

Mayer NA \& Pereira FM (2006) Vigor de clones de umezeiro e pessegueiro 'Okinawa' propagados por estacas herbáceas. Pesquisa Agropecuária Brasileira, 41:883-887.
Picolotto L, Bianchi VJ, Gazolla AN \& Fachinello JC (2007) Diferentes misturas de substratos na formação de mudas de pessegueiro, em embalagem. Scientia Agraria, 8:119-125.

Picolotto L, Manica-Berto R, Pazin D, Pasa M da S, Schmitz JD, Prezotto ME, Betemps DL, Bianchi VJ \& Fachinello JC (2009) Características vegetativas, fenológicas e produtivas do pessegueiro cultivar Chimarrita enxertado em diferentes portaenxertos. Pesquisa Agropecuária Brasileira, 44:583-589.

Reis JMR, Chalfun NNJ \& Reis M de A (2010) Métodos de enxertia e ambientes na produção de mudas de pessegueiro cv. 'diamante'. Pesquisa Agropecuária Tropical, 40:200-205.

Rocha M da S, Bianchi VJ, Fachinello JC, Schmitz JD, Pasa M da S \& Silva JB da (2007) Comportamento agronômico inicial da cv. chimarrita enxertada em cinco porta-enxertos de pessegueiro. Revista Brasileira Fruticultura, 29:583-588.

Telles CA, Biasi LA, Neto URM \& Peters E (2006) Sobrevivência e crescimento de mudas de pessegueiro interenxertadas. Revista Brasileira de Fruticultura, 28:297-300.

Wagner Júnior A, Costa e Silva JO, Santos CEM, Pimentel LD, Negreiros JRS, Alexandre RS \& Bruckner CH (2007) Substratos na formação de mudas para pessegueiro. Acta Scientiarum Agronomy, 29:569-572. 